\title{
Serge Zenkine, L'Expérience du relatif. Le romantisme français et l'idée de culture
}

\author{
Michel Arrous
}

\section{(2) OpenEdition}

1 Journals

\section{Édition électronique}

URL : http://journals.openedition.org/studifrancesi/3767

DOI : 10.4000/studifrancesi.3767

ISSN : 2421-5856

Éditeur

Rosenberg \& Sellier

\section{Édition imprimée}

Date de publication : 1 décembre 2012

Pagination : 580-581

ISSN : 0039-2944

\section{Référence électronique}

Michel Arrous, «Serge Zenkine, L'Expérience du relatif. Le romantisme français et l'idée de culture », Studi Francesi [En ligne], 168 (LVI | III) | 2012, mis en ligne le 30 novembre 2015, consulté le 08 mars 2021. URL : http://journals.openedition.org/studifrancesi/3767 ; DOI : https://doi.org/10.4000/studifrancesi. 3767

Ce document a été généré automatiquement le 8 mars 2021.

\section{(c) 9 (i) $\Theta$}

Studi Francesi è distribuita con Licenza Creative Commons Attribuzione - Non commerciale - Non opere derivate 4.0 Internazionale. 


\section{Serge Zenkine, L'Expérience du relatif. Le romantisme français et l'idée de culture}

Michel Arrous

\section{RÉFÉRENCE}

SERGE ZENKINE, L'EXpérience du relatif. Le romantisme français et l'idée de culture, Paris, Classiques Garnier, 2011, pp. 244.

1 La petite dizaine d'extraits de cette thèse (Moscou, 2001) publiés en France entre 1995 et 2002 avait permis aux dix-neuviémistes d'apprécier l'analyse du relativisme culturel proposée par Serge Zenkine. On pourra désormais s'en faire une idée plus complète. Si l'idée relativiste ou celle de la pluralité des types a un long passé, c'est surtout la culture romantique et son nouveau paradigme intellectuel et esthétique qui en a révisé et transformé la notion et les motifs. De la relativité des mours, en tant qu'objets d'observation, qu'affirmaient les Lumières, on est passé à un relativisme des valeurs «accessibles par voie de sympathie, d'introspection, d'Einfühlung». Après avoir évoqué l'archéologie de cette idée et les grandes oppositions qui l'ont structurée jusqu'à la coupure historico-culturelle de la Révolution et l'essor du romantisme, S. Zenkine en étudie les métamorphoses dans cinq champs bien différents, sinon apparemment disparates ou dont la proximité n'est pas toujours pertinente: l'utopie saint-simonienne en tant que religion intellectuelle et «culturelle», l'expérience des limites saisie à travers l'opposition de la nature et de la culture, par exemple dans la critique de la civilité mondaine et des rapports avec l'Autre réel et géographique (Mme de Staël et l'essence de la civilité française, Custine et la sous-civilisation russe) ou, moins attendu, avec l'autre monde (Nodier, Gautier, Nerval). S. Zenkine n'a d'ailleurs pas omis la situation du traducteur ni celle du rêveur qui ont tous deux affaire à l'Autre, à une forme d'altérité que prétend approcher, voire réduire, une «fidélité» littérale (Courier, Nodier). Suivent des pages plus convenues sur la lutte entre l'ancien et le nouveau - 
mais la modernité reste un concept vague -, sur l'expérience existentielle du voyage dans la culture, avec Stendhal et Nerval: dans le cas du premier, l'analyse, limitée il est vrai au Rome, Naples et Florence de 1817, propose trop rapidement un Stendhal qui en reste «à son utopie de l'homme naturel»; dans le cas du second, l'assimilation classique du voyage ou de l'errance à la recherche des origines ne renouvelle pas la lecture des œuvres, même si est soulignée l'expérimentation tragique sur soi. Très logiquement, l'étude historique de l'idée de culture inclut ces hauts lieux de l'expérience cognitive romantique que sont le musée et la bibliothèque, aboutissement ou accomplissement historique de l'idée de culture et en même temps point de départ de rêveries esthétiques ou érotiques (Gradiva, Arria Marcella). D'où le retour sur l'histoire comique des autodidactes-collectionneurs de Bouvard et Pécuchet et sur l'espèce de mise en musée des choses et des êtres qu'opère la poésie de Mallarmé. Les deux auteurs ayant tenté «d'aller jusqu'au bout de la réalité». À partir d'une définition topique de la culture comme «lieu» où la littérature fait l'expérience de la relativité des valeurs et des conventions, et interprétant la coupure dans le continuum historique qu'opère la crise inaugurale de la modernité, S. Zenkine s'est livré à un examen historico-littéraire du relativisme culturel qui mérite d'être élargi à l'époque contemporaine menacée par l'indifférenciation multiculturaliste. 